Research Article

\title{
Potential Use of Compounds from Neem Leaves (Azadirachta indica Juss) as PPAR $\gamma$ and ER $\alpha$ Inhibitors to Control Breast Cancer Cell Growth In Silico Model
}

\author{
Supriyanto ${ }^{1 *}$, Muhaimin Rifa'i2 ${ }^{2}$ Yunianta ${ }^{3}$, Simon Bambang Widjanarko ${ }^{3}$
}

${ }^{1}$ Postgraduate Program, Faculty of Agriculture, Brawijaya University, Malang, Indonesia, 65145

2Department of Biology, Faculty of Mathematics and Natural Sciences, Brawijaya University, Malang, Indonesia, 65145

3Department of Food Science and Technology, Faculty of Agricultural Technology, Brawijaya University, Malang, Indonesia, 65145

\section{ARTICLE INFO \\ ABSTRACT}

\section{Article History}

Received 30 May 2020

Revised 15 June 2020

Available online 6 July 2020

*Email of author corresponding:

supriyanto@trunojoyo.ac.id

\begin{abstract}
Treatment using herbs is currently growing rapidly. Compounds in herbal plants can cure various degenerative diseases. The study aims to analyze the potency of nimbin, deacetylnimbin, salanin, and deacetylsalanin compounds in the neem leaves extract to inhibit target proteins namely PPAR $\gamma$ and ER $\alpha$. PPAR $\gamma$ is the main regulator of the function of adipose tissue microvascular endothelial cells (aMVECs) while ER $\alpha$ is a protein that mediates all estrogen effects and it is important in the growth of prostate and breast cancer. Inhibition of ER $\alpha$ can prevent the proliferation and growth of breast cancer cells by affecting the performance of estrogen which binds to hormonal receptors and causes inhibition of breast cancer cell proliferation. The results of in silico analysis show that deacetylnimbin can inhibit ER $\alpha$ protein. The docking analysis shows that deacetylnimbin has the potential to replace tamoxifen as a breast cancer drug. The other studies such in vitro and in vivo are needed to validate in silico study.
\end{abstract}

Keywords: Neem leaves, PPAR $\gamma$, ER $\alpha$, breast cancer, in silico study

\section{Introduction}

The number of deaths caused by cancer is increasing. According to World Health Organization (WHO), death cases that are caused by cancer in 2016 were 8.6 million and increased up to 9.6 million in 2018. The main causes of cancer are high body mass index, low consumption, lack of physical activity, smoking, and excessive alcohol consumption. Environmental pollution, food additives, and carcinogenic contamination can also trigger cancer disease.

Several studies have shown that extract of neem leaves has bioactivity which can inhibit the growth of cancer cells [1]. Desacetylnimbin is one of the compounds in the extract of neem leaves which can prevent the growth of breast cancer cells through apoptosis mechanism [2]. Azadirachtin has potential as an inhibitory compound for the growth of cervical cancer cells [3]. However, the mechanism of inhibition of cancer cells at molecular level by those compounds in the neem leaves extract is unclear.

The purpose of this research is to study the potential of compounds in the neem leaves extracts against the peroxisome proliferator-activated receptor gamma (PPAR $\gamma$ ) protein and estrogen receptor alpha (ER $\alpha$ ) which play a role in the growth of cancer cells. PPAR $\gamma$ is the main regulator of the function of adipose tissue microvascular endothelial cells (aMVECs). PPAR $\gamma$ can suppress cancer growth in humans by apoptosis and induction of differentiation. ER $\alpha$ is a protein that mediates all estrogen effects and it is important in the growth of prostate and breast cancer [4]. 
Estrogen plays an important role in development of breast cancer. This compound will bind to estrogen receptors so that complex formation can trigger cell proliferation [5]. Common chemical treatment uses tamoxifen to inhibit the growth of cancer cells. Tamoxifen, an "anti-estrogen" compound, works by competing with estrogen to bind to estrogen receptors in breast cancer cells. Tamoxifen is known as a selective estrogen receptor modulators (SERMs). This compound helps to inhibit the growth and development of breast cancer cells by blocking [6]. The aim of this study is to analyze the potential of nimbin, deacetylnimbin, salanin and deacetylsalanin compounds as PPAR $\gamma$ and ER $\alpha$ inhibitors in the growth of breast cancer in silico model.

\section{Materials and Methods}

\subsection{Materials}

The three-dimensional structure of azadirachtin, nimbin, deacetylnimbin, salanin, and deacetylsalanin compounds is downloaded on the website: https://pubchem.ncbi.nlm.nih.gov/. The structure of PPAR $\gamma$ and ER $\alpha$ target proteins is downloaded on PDB (Protein Data Bank), http://www.rcsb.org/pdb/home/home.do.

\subsection{Determination of Target Protein}

Determination of target protein from bioactive compounds in the neem leaves is conducted using SEA Target Prediction Webserver (http://sea16.docking.org/) and Swiss Target Prediction (http://www.swisstargetprediction.ch/) by entering canonical SMILE from each compound. The approach of the targeted protein prediction is based on the similarity of the composition of the compound inputted with compounds that have been shown to interact with certain proteins.

\subsection{Molecular Docking}

Docking is performed using Autodock Vina in the PyRx 9.5. Proteins used as a target are PPAR (PDB ID 3E00 complex with GW9662 inhibitor) and ER $\alpha$ (PDB ID 3ERT complex with 4-hydroxytamoxifen inhibitor). Both proteins are selected because they are commonly target protein in the breast cancer treatment. PyMol 2.3.1 program is used to visualize the docking results, while LigPlot 2.1 program is used to see amino acid interactions.

\subsection{Preparation of Structure and Molecule Code}

Ligands for docking analysis are nimbin, deacetyInimbin, salanin, and deacetysalanin. The SMILES code of the four ligands is converted to a 3D structure in PDB format using BIOVIA Discovery Studio 4.5 (20). This structure is used for docking ligands. The receptor structure is taken from PDB for PPAR $\gamma$ and ER $\alpha$. The proteins or receptors are prepared using BIOVIA Discovery Studio.

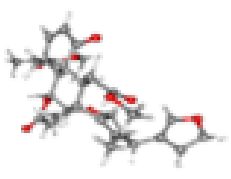

A

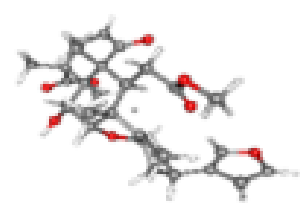

B

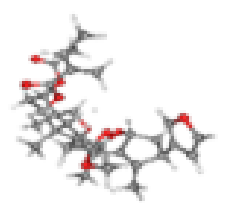

C

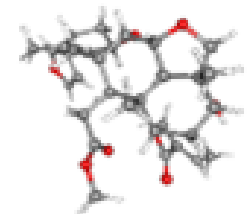

D

Figure 1. Three-dimensional structure of ligands: A) nimbin, B) deacetylnimbin C) salanin, and D) deacetylsalanin.

\subsection{Validation of Molecular Docking Method}

Validation of molecular docking methods is carried out using Autodock Application Tools (Autodock 4.2 and Autogrid) with docking back (redocking) native ligands in HER-2 protein in which the native ligand is removed. Parameter method validation is root mean square deviation (RMSD) which the value can be accepted $\leq 3.0 \AA$.

\section{Result and Discussion}

Hanahan and Weinberg [7] classified characteristics of cancer into several principles which are development, invasion, and metastasis cancer (Hallmarks of Cancer). Therefore, to study the development of cancer and its therapy, the principles and characteristics in the Hallmarks of Cancer need to be considered.

\subsection{Predictions of Target Protein}

Target proteins from bioactive compounds in the neem leaves can be predicted using Swiss Target Prediction to estimate the most possible molecular targets. This prediction is based on a combination of $2 \mathrm{D}$ and $3 \mathrm{D}$ structure similarities. 
The bioactive compounds in the neem leaves are predicted to target proteins which play many roles in the cancer development such as interacting with EGFR in signaling proliferation and with proteins in inflammation, targeting proteins in angiogenesis and cyclin-dependent kinases (play in cell cycles), and being able to target MDM2 that binds p53 to repair DNA damage. The prediction of target proteins by bioactive compounds in the neem leaves is shown in Table 1.

Table 1. The Prediction of Target Proteins

\begin{tabular}{clc}
\hline Compound & \multicolumn{1}{c}{ Target Protein } & Pa (Probability of Activity) \\
\hline Deacetylnimbin & Macrophage migration inhibitory factor (MIF) & 0.2800 \\
& Epidermal growth factor receptor (EGFR) & 0.2800 \\
& Interleukin-8 receptor CXCR2, CXCR1 & 0.1032 \\
& Vascular endothelial growth factor receptor 1 (FLT1) & 0.1032 \\
& Cyclin-dependent kinase (CDK) & 0.1032 \\
Azadirachtin & MDM2 & 0.1032 \\
Nimbin & Epidermal growth factor receptor (EGFR) & 0.0499 \\
& Macrophage migration inhibitory factor (MIF) & 0.3000 \\
& MDM2 & 0.0900 \\
& Colony stimulating factor 1 receptor (CSF1R) & 0.0900 \\
\hline
\end{tabular}

\subsection{Molecular Docking Analysis}

Docking performed in this study is specific docking by duplicating of the interaction between target proteins and ligand control. Docking is a method for predicting the strength of interactions between receptors and ligands based on binding affinity values. Strong interaction between receptors and ligands occurs if the value of binding affinity is more negative. Deacetylnimbin and nimbin compounds are more potential as ER $\alpha$ inhibitor than the other bioactive compounds. Docking analysis to PPAR $\gamma$ as protein target does not give good result so it is not analyzed further. The results of ER $\alpha$ docking with tamoxifen as control can be seen in Table 2 .

Table 2. Result of ESRa Docking with Tamoxifen Control

\begin{tabular}{lc}
\hline \multicolumn{1}{c}{ Ligand } & Binding Affinity (kcal/mol) \\
\hline Deacetylnimbin & -6.3 \\
Nimbin & -6.3 \\
Deacetylsalanin & -2.8 \\
Salanin & 4.4 \\
Tamoxifen (Control) & -9.8 \\
\hline
\end{tabular}

The result of docking shows that deacetylnimbin and nimbin have a high enough affinity to interact and inhibit the ERa activity with a binding affinity value of $-6.5 \mathrm{kcal} / \mathrm{mol}$. The value is closest to the binding affinity value of tamoxifen as a control, $-9.8 \mathrm{kcal} / \mathrm{mol}$.

\subsection{Docking Analysis using Discovery Studio}

Besides the value of binding affinity, analysis with Discovery Studio (DS) is also carried out to study interactions between ligands and proteins at the molecular up to the atomic level. The analysis shows deacetylnimbin interacts with the hydrophobic cave of ERa protein. In chemical bonds, interaction formed between amino acids of ERa and deacetylnimbin is hydrogen bond. Furthermore, hydrophobic interactions are also found on several sites of the protein as well as the ligand (Figure 2).

The number of hydrogen bonds formed in protein-ligand interactions contributes to the stability of the complex structure, in other words, the more number of hydrogen bonds formed, the more complex structure will be. Four hydrogen bonds in the protein-ligand interaction, it can form a stable complex structure [8]. Besides its binding affinity, analysis using DS shows interactions of hydrophobic and strong hydrogen bonds between ERa protein and deacetylnimbin. The hydrogen bonds and hydrophobic bonds optimization in protein-ligand interactions also influence bond stability between the ligand and its target [9]. When a sufficient number of hydrogen bonds are accompanied by hydrophobic interactions, it can be said that the interactions between the two molecules are quite strong interaction.

The stability of ERa protein and deacetylnimbin can be achieved when they bind. One possible mechanism to inhibit cancer development using deacetylnimbin is by preventing the interaction of ERa with its original ligand which has mitogenic signaling activity. 


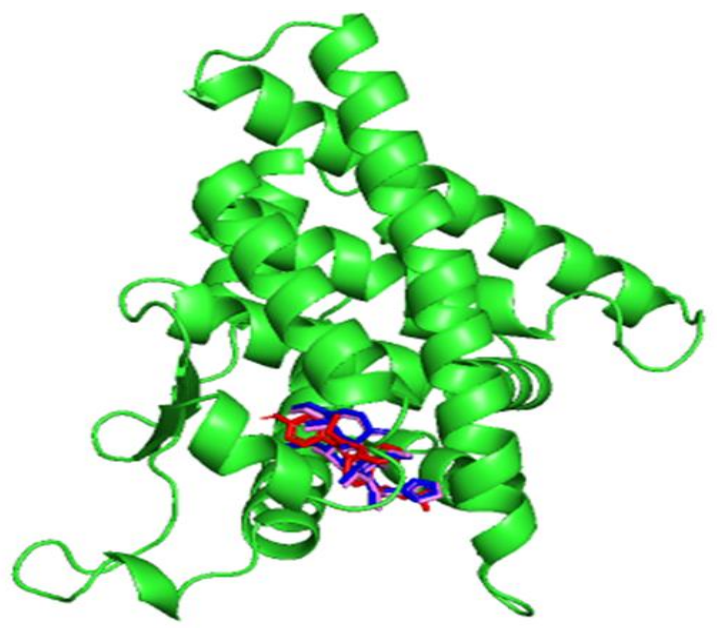

Figure 2. Visualization of ERa between ligands - tamoxifen (red), nimbin (blue), and deacetylnimbin (violet).

After calculating the binding affinity value, it is necessary to do further analysis of the interaction of amino acids between proteins and ligands using the LigPlot program. Based on LigPlot analysis, interaction of several amino acids is the same between bioactive compounds in the neem leaves and tamoxifen (control). It can be predicted that the bioactive compound in the neem leaves can interact with ERa similar to interactions of ERa and tamoxifen.

Table 3. Visualization using LigPlot Program

\begin{tabular}{|c|c|c|c|}
\hline Compounds & Hydrophobic Bond Position & Hydrogen Bond Position & Hydrogen Bond Distance $(\AA)$ \\
\hline Tamoxifen & $\begin{array}{l}\text { LEU387, LEU349, EU346, } \\
\text { MET421, LEU428, LY420, } \\
\text { MET343, GLU419, IS524, } \\
\text { GLY521, LEU525, RP383, } \\
\text { ALA350, LEU384, THR347 }\end{array}$ & GLU353, ARG394 & $\begin{array}{l}\text { ARG394 : } 2.80 \\
\text { GLU353 : } 2.75\end{array}$ \\
\hline DeacetyInimbin & $\begin{array}{l}\text { LEU525, TRP383, HR347, } \\
\text { LEU387, ALA350, LU353, } \\
\text { ARG394, MET388, HE404, } \\
\text { ILE424, LEU384, HIS524, } \\
\text { GLY521, MET343, GLY420 }\end{array}$ & LEU346 & LEU346 : 3.26 \\
\hline Nimbin & $\begin{array}{c}\text { TRP383, LEU525, ILE424, } \\
\text { HIS524, MET343, GLY521, } \\
\text { MET388, GLY420, LEU346, } \\
\text { LEU391, LEU384, GLU353, } \\
\text { PHE404, ARG394, LEU349, } \\
\text { ALA350, THR347 } \\
\end{array}$ & Not identified & \\
\hline
\end{tabular}

Based on Table 3, it can be seen that deacetylnimbin and nimbin have 10 and 9 amino acids, respectively, which are the same as the amino acids of tamoxifen (control). The result proves that deacetylnimbin is more potential than nimbin. The hydrogen bond distance of ARG394 and GLU353 is 2.80 and $2.75 \AA$, respectively.

\subsection{Validation of Molecular Docking Method}

Validation of molecular docking methods was done by redocking native ligand of ERa with pre-prepared ERa protein. Parameter of method validation is RMSD value that shows the distance of deviation from position native ligand binding with protein after docking to the native bonding position of the real ligand. The score of RMSD value can also be called distance bond. RMSD value obtained in this research is $0.7 \AA$ which means the molecular docking method used has been validated. The visualization of interactions of molecular docking can be seen in Figure 2. The small RMSD value reflects the ligand position of the redocking result is closer to the crystallography result. 


\section{Conclusion}

Based on in silico analysis, deacetylnimbin is the most potential candidate to inhibit ERa protein compared to other compounds based on its binding affinity. It indicates that deacetylnimbin potent to replace tamoxifen drug to treat breast cancer. In vitro and in vivo studies are needed to validate in silico study.

\section{References}

[1]. S. M. Patel, K. C. N. Venkata, P. Bhattacharyya, G. Sethi, \& A. Bishayee, "Potential of Neem (Azadirachta indica L.) for Prevention and Treatment of Oncologic Diseases," Seminars in Cancer Biology, vol. 40-41, pp. 100-115, 2016.

[2]. A. Arumugam, R. Subramani, S. Nandy, S. Powell, M. Velazquez, A. Orozco, A. Galvez, \& R. Lakshmanaswamy, "Desacetyl nimbinene Inhibits Breast Cancer Growth and Metastasis through Reactive Oxygen Species Mediated Mechanisms," Tumour Biology, vol. 37, pp. 6527-6537, 2016.

[3]. T. Singh, H. S. Saini, S. V. Ranganayakulu, S. Ravi, \& K. Sudhakar, "Molecular Docking Assisted Isolation of Azadirachtin-A, from Seeds of Azadirachta indica Extract against Cervical Cancer," Indian Journal of Science and Technology, vol. 10, no. 12, pp. 1-5, 2017.

[4]. A. Miller, H. Vo, L. Huo, C. Roca, P. J. Schmidt, \& D. R. Rubinow, "Estrogen Receptor Alpha (ESR-1) Associations with Psychological Traits in Women with PMDD and Controls," Journal of Psychiatric Research, vol. 44, no. 12, pp. 788-794, 2010.

[5]. V. Swamy, J. Deshpande, J. S. Pathageri, V. Kothekar, \& S. Padhye, "Molecular Docking Studies on Estrogen Receptor - A and Chalcone Derivatives," International Journal of Advances in Pharmacy and Biological Sciences, vol. 1, no. 3, pp. 87-93, 2011.

[6]. F. Yu \& W. Bender, "The Mechanism of Tamoxifen in Breast Cancer Prevention," Breast Cancer Research, vol. 3, no. A74, 2001.

[7]. D. Hanahan \& R. A. Weinberg, "Hallmarks of Cancer: The Next Generation," Cell, vol. 144, pp. 646-674, 2011.

[8]. A. Elengoe, M. A. Naser, \& S. Hamdan, "Modeling and Docking Studies on Novel Mutants (K71L and T204V) of the ATPase Domain of Human Heat Shock 70 kDa Protein 1," International Journal of Molecular Sciences, vol. 15, no. 4, pp. 6797-6814, 2014.

[9]. R. Patil, S. Das, A. Stanley, L. Yadav, A. Sudhakar, \& A. K. Varma, "Optimized Hydrophobic Interactions and Hydrogen Bonding at the Target-Ligand Interface Leads the Pathways of Drug-Designing," Plos One, vol. 5, no. 8, pp. e12029, 2010. 